\title{
Beneficial Effects of Sambucus nigra in Chronic Stress-Induced Neurobehavioral and Biochemical Perturbation in Rodents
}

\author{
Sachin Neekhra ${ }^{1}$, Himani Awasthi ${ }^{1, *}$, Dharmchand Prasad Singh ${ }^{2}$
}

Sachin Neekhra ${ }^{1}$, Himani Awasthi ${ }^{1}, *$, Dharmchand Prasad Singh ${ }^{2}$

'Amity Institutes of Pharmacy, Amity University Uttar Pradesh, Near Malhaur Station, Gomati Nagar Extension, Lucknow (U.P.) - 226010, INDIA.

${ }^{2}$ College of Pharmacy, SR Group of Institutions, Ambabai, Jhansi (U.P.) - 284002, INDIA.

\section{Correspondence}

\section{Himani Awasthi}

Amity Institutes of Pharmacy, Amity

University Uttar Pradesh, Near Malhaur

Station, Gomati Nagar Extension, Lucknow (U.P.) - 226010, INDIA.

E-mail: amitypharmacology123@gmail.com

\section{History}

- Submission Date: 17-09-2020;

- Review completed: 18-10-2020;

- Accepted Date: 10-11-2020.

DOI : 10.5530/pj.2021.13.22

Article Available online

http://www.phcogj.com/v13/i1

Copyright

(C) 2021 Phcogj.Com. This is an openaccess article distributed under the terms of the Creative Commons Attribution 4.0 International license.

\section{ABSTRACT}

Background: Stress is the causative factor for various diseases and disorders faced by the majority of the diseased population. The leaves of Sambucus nigra (S. nigra) are attributed to neuropharmacological properties as per literature. Considering the above, the $S$. nigra hydroalcoholic extract was tested for adaptogenic activity in animals. Objective: The study deals with the evaluation of $S$. nigra hydroalcoholic extract for adaptogenic activity using cold immobilization and footshock induced stress. Materials and Methods: The S. nigra hydroalcoholic extract (200 and $400 \mathrm{mg} / \mathrm{kg}$ ) was administered to treatment groups 1 hour before footshock for 14 consecutive days and cold immobilization stress for 10 consecutive days, respectively. The current work was carrying out to investigate the adaptogenic activity of $S$. nigra against footshock stress induced perturbations in behaviour (sexual behaviour, depression, and cognitive dysfunction). Suppressed male sexual behaviour, percentage active avoidance response and duration of immobility in footshock stress were used as the stress indices. Additionally, liver function (SGOT, SGPT, and ALP), lipid profiles (TC, TG, HDL, LDL, and VLDL) and differential leukocytes counts (neutrophils, eosinophils, lymphocyte, and monocyte) in cold immobilization stress were assessed in terms of stress indices. Diazepam $(1 \mathrm{mg} / \mathrm{kg})$ was served as the standard adaptogenic agent as per literature review for comparison. Results: All these chronic stress-induced perturbations were reversed, dose-dependently by $S$. nigra (2000 and $400 \mathrm{mg} / \mathrm{kg}$ ) and diazepam (1 mg/kg). The dose group $400 \mathrm{mg} / \mathrm{kg} \mathrm{p.O.} \mathrm{of} \mathrm{S.} \mathrm{nigra}$ hydroalcoholic extract for adaptogenic activity in cold immobilization and footshock induced stress method showed significant variation $(P<0.1)$ when is compared with the stress control group. Conclusion: S. nigra hydroalcoholic extract showed significant adaptogenic activity was indicated by qualitatively results comparable to diazepam, against a range of biochemical and behavioural perturbations induced by chronic stress.

Key words: Active avoidance response; Cold immobilization; Footshock induced stress; Lipid profiles; Sexual behaviour; Sambucus nigra.

\section{INTRODUCTION}

There is comprehensive experimental and clinical sign that several aspects of the behavioural, endocrine and immune systems are severely compromised following exposure to chronic stress. ${ }^{1}$ The stress effects appear to be determined by the duration rather than the intensity of the external or internal stressful stimuli. Thus, acute and transient stress, of a severe nature, may be less harmful than mild stress continued over a length of time. ${ }^{2}$ Additional main aspect, which initiates and exacerbates stress- induced effects, is the failure of the body to cope with the stress condition. The introduction of the factor of unpredictability makes it difficult for the individual to adapt, and therefore cope, to the stressor. ${ }^{3}$ Stress has been hypothesised that a variety of diseased states induced their involvement of etiopathogenesis, ranging from psychiatric disorders like anxiety and depression, endocrine disorders including diabetes mellitus, male impotency, and cognitive dysfunctions, to diseases like hypertension, ulcerative colitis and peptic ulcer. ${ }^{4}$ Therapy of stress includes an alternative system of medicine, allopathic which is being currently available, but allopathic medicine drugs especially benzodiazepines category is having a various adverse effects (side effect, tolerance, and dependence) which limit its uses. Thus herbal formulation needs for management of stress on long term use. ${ }^{5}$ Rasayanas of Ayurveda are effective adaptogenic agents because they seem to prolong, Selye's proposed stage of the "General adaptation syndrome", the stage of resistance to stress, and prevent the final and third stage of exhaustion. ${ }^{6}$

In the current scenario, we need safer and economic herbal drugs as adaptogenic agents that can withstand stress without modifying the biological functions of the body. Plant Adaptogens like Withania somnifera ${ }^{7}$, Elutherococcussenticosus ${ }^{8}$, Panax ginseng ${ }^{9}$, Васора monniera ${ }^{10}$, Sidacordifolia ${ }^{11}$, Ocimum sanctum ${ }^{12}$, Butea frondosa $a^{13}$, and Hypericum perforatum ${ }^{14}$ were reported.

Traditionally, Sambucus nigra (familyCaprifoliaceae) leave and flowers used to treat epilepsy, showed neurobiology activity.

S. nigra is a good source of anthocyanins, vitamins, calcium and iron. It also contains phenolic compounds such as flavonoids, tannins, and coumarins. ${ }^{15-16}$ As per literature review, Tea from $S$.

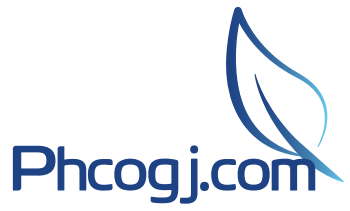

Cite this article: Neekhra S, Awasthi H, Singh DCP. Beneficial Effects of Sambucus nigra in Chronic Stress-Induced Neurobehavioral and Biochemical Perturbation in Rodents. Pharmacog J. 2021;13(1): 155-61. 
nigra leaves was used as sedative for relieving the pain. ${ }^{17}$ Although, it's having good antioxidant, nitric oxide scavenging ${ }^{18}$ and neurobiological activities ${ }^{19}$ therefore that $S$. nigra can used as an adaptogenic activity. Therefore, we attempt to investigate beneficial Effects of Sambucus nigra hydroalcoholic extract on cold immobilization and foot-shock induced neurobehavioral perturbation in rodents.

\section{MATERIALS AND METHODS}

\section{Animal}

Male Wistar rats were selected randomly from the animal house having a uniform weight of $160 \pm 20 \mathrm{~g}$. The room temperature was kept at $22 \pm 2^{\circ} \mathrm{C}$ with free access to water and food. Before the beginning of the experiment, animals were shifted to the laboratory and food and water were removed. All conditions were maintained according to the CPCSEA guideline. The study protocol was permitted by the institutional animal ethical committee. (Approve Ref No. SRGI/ COP/A/29/2016, CPCSEA Reg No. 1624/PO/a/CPCSEA)

\section{Plant material}

The plant material (leaves of $S$. nigra) was collected from the Forest Research Institute (FRI), Dehradun, Uttarakhand, India, and authenticated by taxonomist in Systemic botany Discipline, Botany Division, Forest Research Institute, Dehradun. The voucher specimen of the plant was deposited in the herbarium for future reference.

\section{Preparation of extract}

The dried powdered material (leaves of $S$. nigra) was taken and subjected to solvent extraction. The extraction was carried out for $16 \mathrm{~h}$ with the hydroalcoholic solvent using the material to solvent ratio of 1:5 (w/v).

The hydroalcoholic extract was concentrated by evaporation of the solvent at low temperature till complete drying. Dried extract material was weighed and calculated the different extractive values.

\section{Fourier transform infrared spectroscopy (FTIR)}

A Fourier-transform infrared spectrometer (Model: PerkinElmer Spectrum BX, PerkinElmer, Massachusetts, USA) was used to study the IR characteristics of $S$. nigra hydroalcoholic extract. Dried sample ( $\sim 2 \mathrm{mg}$ ) were weighed individually and transferred into agate mortar and pestle. The individually weighed samples mixed uniformly in such a way with potassium bromide that formed a homogenous mixture. The potassium bromide should have FT-IR grade in which weighing quantity was taken $200 \mathrm{mg}$. At a pressure of $10 \mathrm{Ton}$, this mixture was compressed to achieve thin, transparent discs on a mini hand press. The sample discs were scanned to obtain infrared spectra in the wavelength range of 4000 to $400 \mathrm{~cm}^{-1}$ at a resolution of $4 \mathrm{~cm}^{-1}$. The obtained spectra were processed and analyzed using instrument software accompanying the instrument. ${ }^{20}$

\section{Administration of the extracts}

S. nigra hydroalcoholic extract was dissolved in distilled water. The diazepam was suspended in $2 \%$ gum acacia, administrated intraperitoneally (i.p.) before $30 \mathrm{~min}$ of induction of stress. Hydroalcoholic extract of two different dose levels $200 \mathrm{mg} / \mathrm{kg}$ and 400 $\mathrm{mg} / \mathrm{kg}$ were administrated $1 \mathrm{hr}$ before the induction of stress.

\section{Cold immobilization stress}

S. nigra hydroalcoholic extract was tested using this model at different doses. The rats were divided into five groups of five animals each of both sex and treated with respective extracts at a dose of 200 and 400 $\mathrm{mg} / \mathrm{kg}$ b.w. orally one hour before stress exposure daily of 10 days in cold immobilization stress.
The stress was induced by exposing rats (five groups) to the cold condition of $4-7{ }^{\circ} \mathrm{C}$ for $4 \mathrm{~h}$. The rats were left from their home cages and individually placed in plastic containers with a partition to separate individual rats. The refrigerator had placed containers which were maintained at temperature from 4 to $7^{0} \mathrm{C}$. Rats were returned to home cages after $4 \mathrm{~h}$. This procedure was repeated for 10 days at a specific time between 12:00 noon to 4:00 p.m. Rats were free to food and water, on the $11^{\text {th }}$ day animals were sacrificed by cervical dislocation, blood was collected from the arterial jugular and serum was separated from some part of collected blood. The serum was used for the estimation of various biochemical parameters using different biochemical kits (Erba/ Span Kits). ${ }^{21}$

\section{Footshock induced stress}

Stress protocol described by Armando was used. ${ }^{22}$ During 14 consecutive days, Footshock stress through a grid floor in a shock chamber was applied to rats for $1 \mathrm{~h}$ daily. The duration of each shock $(2 \mathrm{~mA})$ and the interval between the shocks was randomly programmed between 3 and $5 \mathrm{sec}$ and 10 and $110 \mathrm{sec}$, respectively. After the last shock procedure on day 14 , other test procedure was performed. ${ }^{23}$

\section{» Experimental methods \\ » Cognitive Dysfunction}

Active Avoidance Test was used to investigate the consequence of stress on retention of a learned task as memory:

\section{» Behavioral despair test}

Rats were forced to swim individually in vessel $(45 \times 40 \times 30 \mathrm{~cm})$ with a water level of $20 \mathrm{~cm}$, which ensured that the rat's feet does not touch the floor of the vessel and that it could not scramble out of it. The rat was allowed to swim for $10 \mathrm{~min}$. Thereafter, during the next $5 \mathrm{~min}$, the total period of immobility, charac-terized by complete cessation of swimming with the head floating above water level, was noted. This immobility period, after initial frenzied attempts to escape, was postulated to represent "behavioral despair" ${ }^{24}$

\section{»Active Avoidance Test}

Rats were skilled for an active avoidance task before exposing them to stress. During training, the rats were positioned in the electrified grid floor and allowed to accustom for $5 \mathrm{~min}$. Thereafter, the rats were exposed to $15 \mathrm{sec}$ of a buzzer stimulus (conditioned stimulus) which was followed by electric shock $(1 \mathrm{~mA}, 50 \mathrm{~Hz})$ given through the grid floor (unconditioned stimulus). On day lof the test procedure, the rats were given at least 10 trials, with an inter-trial interval of $60 \mathrm{~min}$, until they achieved the criterion of $100 \%$ avoidance response of leaping to the unelectrified wooden pole during conditioned stimulus. The test procedure was again performed on day 14 in order to investigate the retention of the active avoidance learning. ${ }^{25}$

\section{» Sexual Behavior}

A male rat was placed in a cage in a dimly-lit room for $10 \mathrm{~min}$ with 2 oestrinized (sequentially treated with oestradiol valerate $5 \mu \mathrm{g} / \mathrm{rat}$, followed $48 \mathrm{hr}$ later by hydroxyprogesterone $1.5 \mathrm{mg} / \mathrm{rat}, \mathrm{sc}$ ) female rats, The parameters observed as total number of mounts was counted..$^{26}$

\section{Statistical analysis}

All the values are expressed as mean \pm SEM. Statistical differences between means were determined by one way ANOVA followed by Dunnett's post hoc test. $P<0.05$ was considered as significant. The statistical analysis was done using Instat ${ }^{\circledR}$ software (Graph pad Inc., Santabarba, CA) 


\section{RESULTS}

\section{IR Spectrum of hydroalcoholic extract of Sambucus nigra-}

There is a broad peak in spectra in the range of 3410.02-3500 which shows -OH (Alcohol group) and a peak around 2972.80 which shows presence of $-\mathrm{CH}$ i.e. Methane group and there is a peak around 1625.04 which shows presence of conjugated carbonyl, there is a decrease in frequency of carbonyl from 1700 to 1625.04 (strong point in spectra) and lower frequencies i.e.1419, 1154, are - $\mathrm{CH}$ bending and heteroatoms bind to carbon falls in the ranges between $700-800 \mathrm{~cm}^{-1}$. There is no other peak in spectra of other functional group. Possibility of kaempferol is confirmed.

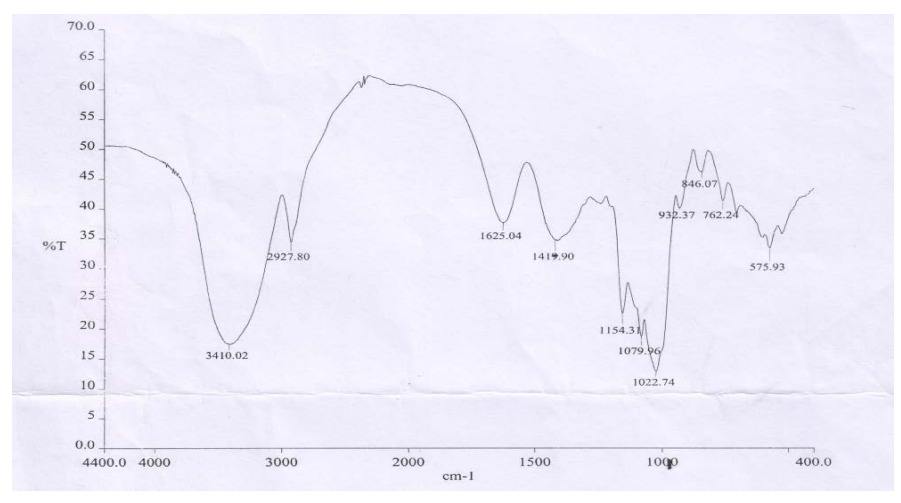

\section{Evaluation of adaptogenic activity of extract in rats}

\section{Effect on liver function test}

Serum liver function test parameters like SGOT, SGPT and ALP were found to be increased in cold immobilization stress in rats which were significantly decreased $\left({ }^{*} P<0.5,{ }^{* *} P<0.1,{ }^{* * *} P<0.05\right)$ in rats on pretreatment with S. asper hydroalcoholic extract (200 and $400 \mathrm{mg} / \mathrm{kg}$ ) and diazepam. $(1 \mathrm{mg} / \mathrm{kg})$

\section{Effect on lipid profiles}

Lipid profiles (TC, TG, HDL, LDL, and VLDL) were found to be altered in cold immobilization stress on rats. Increased level of lipid profiles was significantly reduced $\left({ }^{\star} P<0.5,{ }^{* *} P<0.1,{ }^{* *} P<0.05\right)$ on pretreatment with S. asper hydroalcoholic extract (200 and $400 \mathrm{mg} / \mathrm{kg}$ ) and diazepam $(1 \mathrm{mg} / \mathrm{kg})$

\section{Effect on differential leukocyte count}

Differential leukocyte counts (Neutrophils, Eosinophils, Lymphocyte, and Monocyte) were increased in cold immobilization stress model on rats. Increased level of differential leukocyte counts was significantly reduced $\left({ }^{\star} P<0.5,{ }^{* *} P<0.1,{ }^{* *} P<0.05\right)$ on pretreatment with $S$. asper hydroalcoholic extract (200 and $400 \mathrm{mg} / \mathrm{kg}$ ) and diazepam $(\mathrm{mg} / \mathrm{kg})$

Effect of Sambucus nigra on footshock stress induced changes in suppression of sexual behaviour, memory deficit in active avoidance response, and swim stress immobility

Footshock stress significantly increased the duration of immobility as well as decreased the sexual behaviour (number of mounting) and the retention of acquired active learning. S. nigra $(200$ and $400 \mathrm{mg} / \mathrm{kg}$, p.o.) and diazepam ( $1 \mathrm{mg} / \mathrm{kg}$ i.p.) significantly reversed $\left({ }^{\star} P<0.5,{ }^{\star \star} P<\right.$ $\left.0.1,{ }^{* * \star} P<0.05\right)$ stress induced neuro and sexual behaviour changes as indicated by decreased the duration of immobility, increased number of mounting and retention of acquired active learning.

\section{DISCUSSION}

When the body is unable to cope with the stress situation, various biological and behavioural events of external as well as internal stress occurs, which may perturb homeostasis and also leads to various clinical diseases. So to understand these factors, stress research seems to be essential in laboratory animals. ${ }^{27}$

It has now been proposed that stressors be classified based upon dimensions of intensity, frequency of exposure and the duration of stress exposure. The studies observed so far mark that $S$. nigra hydroalcoholic extract had a protective action on the animals against the alterations inflicted due to cold stress, such as changes in the serum liver function test and lipid profiles levels, and differential leukocyte count. It results in hypothalamic-pituitary axis (HPA) activation, leading to release of the adrenocortical hormone responsible for stressful response further releasing of corticosterone hormone. ${ }^{28}$ In cold immobilization stress repeated exposure of rats for 10 days to the stressful condition was carried, as it causes a wide range of physiological and neuroendocrine changes. ${ }^{29}$

The cold stress exposed to rat leads to elevated levels of SGPT, SGOT and ALP due to secretion of corticosterone from cortex, adrenaline from medulla and nor-adrenaline from sympathetic nerve terminals which supply substrate for energy metabolism and the confirm the ATP demand in the muscles, CNS, and other organs. ${ }^{30}$

In stress conditions, the secondary substrate such as fat used for glucose formation and gluconeogenesis proceed in response to corticosterone. The transfer of $\gamma$-amino groups of alanine and aspartate are being catalyzed by ALT and AST enzymes respectively, to $\gamma$ - keto group of keto-gluterate, resulting in the formation of oxaloacetic acid and pyruvic acid (Barua et al., 2018). ${ }^{31}$ The $400 \mathrm{mg} / \mathrm{kg}$ dose of $S$. nigra hydroalcoholic extract caused significant reduction $(P<0.1)$ in the levels

Table 1: Effect of S. nigra hydroalcoholic extract on liver function test.

\begin{tabular}{|c|c|c|c|c|}
\hline S. No & Treatment Group & $\begin{array}{l}\text { SGOT } \\
\text { (U/L) }\end{array}$ & $\begin{array}{l}\text { SGPT } \\
\text { (U/L) }\end{array}$ & $\begin{array}{l}\text { ALP } \\
\text { (U/L) }\end{array}$ \\
\hline 1 & Normal Control $(10 \mathrm{ml} / \mathrm{kg})$ & $143.550 \pm 9.910$ & $98.94 \pm 2.57$ & $167.22 \pm 6.24$ \\
\hline 2 & Stress Control $(10 \mathrm{ml} / \mathrm{kg})$ & $270.560 \pm 6.730^{\# \# \#}$ & $177.78 \pm 4.44^{\# \# \#}$ & 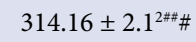 \\
\hline 3 & S. nigra hydroalcoholic extract $(200 \mathrm{mg} / \mathrm{kg})$ & $240.48 \pm 7.04^{*}$ & $150.71 \pm 6.41^{*}$ & $288.82 \pm 5.78^{*}$ \\
\hline 4 & S. nigra hydroalcoholic extract $(400 \mathrm{mg} / \mathrm{kg})$ & $226.040 \pm 7.907^{* *}$ & $148.95 \pm 5.89^{* *}$ & $275.67 \pm 6.20^{\star *}$ \\
\hline 5 & Standard drug diazepam $(1 \mathrm{mg} / \mathrm{kg})$ & $158.790 \pm 2.640^{* * *}$ & $111.59 \pm 7.124^{* * *}$ & $214.30 \pm 8.37^{* * *}$ \\
\hline
\end{tabular}

Value are expressed as mean $\pm \operatorname{SEM}(n=5)$, one way ANOVA followed by Dunnett's test; ${ }^{* * *} P<0.001$ when compared to normal control ${ }^{*} P<0.5,{ }^{* *} P<0.1,{ }^{* * *} P<0.05$ when compared with the stress group. 
Table 2: Effect S. nigra hydroalcoholic extract on lipid profiles level in rats.

\begin{tabular}{ccccccc}
\hline S. No. & Treatment group & $\begin{array}{c}\text { TC } \\
(\mathrm{mg} \%)\end{array}$ & $\begin{array}{c}\text { TG } \\
(\mathrm{mg} \%)\end{array}$ & $\begin{array}{c}\text { HDL } \\
(\mathrm{mg} \%)\end{array}$ & $\begin{array}{c}\text { LDL } \\
(\mathrm{mg} \%)\end{array}$ & $\begin{array}{c}\text { VLDL } \\
(\mathrm{mg} \%)\end{array}$ \\
\hline 1 & Normal Control $(10 \mathrm{ml} / \mathrm{kg})$ & $75.66 \pm 1.861$ & $65.54 \pm 1.09$ & $53.71 \pm 3.32$ & $20.44 \pm 0.59$ & $13.10 \pm 0.21$ \\
2 & Stress Control $(10 \mathrm{ml} / \mathrm{kg})$ & $96.32 \pm 1.44^{* * *}$ & $98.86 \pm 2.80^{* * *}$ & $13.96 \pm 3.21^{* * *}$ & $40.3 \pm 1.13^{* * *}$ & $19.69 \pm 0.56^{* * *}$ \\
3 & S. nigra hydroalcoholic extract $(200 \mathrm{mg} / \mathrm{kg})$ & $86.26 \pm 1.99^{*}$ & $89.86 \pm 1.80^{*}$ & $26.14 \pm 3.17^{*}$ & $34.82 \pm 1.48^{*}$ & $17.85 \pm 0.48^{*}$ \\
4 & S. nigra hydroalcoholic extract $(400 \mathrm{mg} / \mathrm{kg})$ & $81.98 \pm 1.62^{* *}$ & $71.66 \pm 3.89^{* *}$ & $28.08 \pm 2.33^{* *}$ & $33.54 \pm 1.57^{* *}$ & $17.24 \pm 0.42^{* *}$ \\
5 & Standard diazepam $(1 \mathrm{mg} / \mathrm{kg})$ & $76.33 \pm 2.07^{* * *}$ & $67.16 \pm 3.65^{* * *}$ & $39.77 \pm 3.84^{* * *}$ & $22.18 \pm 1.13^{* * *}$ & $13.43 \pm 0.32^{* * *}$ \\
\hline
\end{tabular}

Value are expressed as mean $\pm \operatorname{SEM}(n=5)$, one way ANOVA followed by Dunnett's test; ${ }^{* * *} P<0.001$ when compared to normal control ${ }^{\star} P<0.5$, ${ }^{* *} P<0.1$, ${ }^{* * *} P<0.05$, when compared with the stress group

Table 3: Effect of S. nigra hydroalcoholic extract on differential leukocyte count in rats.

\begin{tabular}{ccccc}
\hline \multirow{2}{*}{ S. No. } & \multirow{2}{*}{ Treatment Group } & NUMBER OF MOUNTING & \multicolumn{2}{c}{ DURATION OF IMMOBILITY } \\
\cline { 3 - 5 } & & (N) & day $1(\mathrm{Sec})$ & day 14 (Sec) \\
\hline 1 & Normal Control $(10 \mathrm{ml} / \mathrm{kg})$ & $10 . \pm 0.58$ & $122.8 \pm 1.15$ & $125.8 \pm 0.66$ \\
2 & Stress Control $(10 \mathrm{ml} / \mathrm{kg})$ & $4.2 \pm 0.73^{* * *}$ & $170.6 \pm 0.92^{* * *}$ & $239.6 \pm 1.8^{* * *}$ \\
3 & S. nigra hydroalcoholic extract $(200 \mathrm{mg} / \mathrm{kg})$ & $8.61 \pm 0.7^{*}$ & $143.4 \pm 1.4^{*}$ & $179.4 \pm 1.9^{*}$ \\
4 & S. nigra hydroalcoholic extract $(400 \mathrm{mg} / \mathrm{kg})$ & $8.6 \pm 0.6^{* *}$ & $135.620 \pm 2.1^{* *}$ & $171.8 \pm 1.4^{* *}$ \\
5 & Standard drug diazepam $(1 \mathrm{mg} / \mathrm{kg})$ & $9.6 \pm 0.5^{* * *}$ & $131.8 \pm 1.5^{* * *}$ & $154.790 \pm 1.8^{* * *}$ \\
\hline
\end{tabular}

Value are expressed as mean $\pm \operatorname{SEM}(n=5)$, one way ANOVA followed by Dunnett's test; ${ }^{\sharp * *} P<0.001$ when compared to normal control ${ }^{\star} P<0.5$, ${ }^{\star \star} P<0.1$, ${ }^{* * \star} P<0.05$, when compared with the stress group.

Table 4: Effect of S. nigra hydroalcoholic extract on neuro and sexual behaviour changes and swim stress immobility in rats.

\begin{tabular}{ccc}
\hline S. No. & Treatment Group & ACTIVE AVOIDANCE RESPONSE ON DAY 14 (\%) \\
\hline 1 & Normal Control $(10 \mathrm{ml} / \mathrm{kg})$ & 80 \\
2 & Stress Control $(10 \mathrm{ml} / \mathrm{kg})$ & $20^{\mathrm{a}}$ \\
3 & S. nigra hydroalcoholic extract $(200 \mathrm{mg} / \mathrm{kg})$ & $46.67^{\mathrm{b}}$ \\
4 & S. nigra hydroalcoholic extract $(400 \mathrm{mg} / \mathrm{kg})$ & $70^{\mathrm{b}}$ \\
5 & Standard drug diazepam $(1 \mathrm{mg} / \mathrm{kg})$ & $73.37^{\mathrm{b}}$ \\
\hline
\end{tabular}

Value are expressed as mean $\pm \operatorname{SEM}(n=5)$, one way ANOVA followed by Dunnett's test; ${ }^{* * *} P<0.001$ when compared to normal control ${ }^{*}$ $P<0.5,{ }^{* *} P<0.1,{ }^{* * *} P<0.05$, when compared with the stress group.

Table 5: Effect of S. nigra hydroalcoholic extract on memory deficit in active avoidance response

\begin{tabular}{|c|c|c|c|c|c|}
\hline S. No. & Treatment Group & Neutrophils & Eosinophils & Lymphocyte & Monocyte \\
\hline 1 & Normal Control $(10 \mathrm{ml} / \mathrm{kg})$ & $23.6 \pm 0.92$ & $2.40 \pm 0.24$ & $74.6 \pm 1.56$ & $6.6 \pm 0.2$ \\
\hline 2 & Stress Control $(10 \mathrm{ml} / \mathrm{kg})$ & $35.01 \pm 1.14^{\# \# \#}$ & $3.8 \pm 0.2^{\#}$ & $66.8 \pm 1.49^{\#}$ & $6.8 \pm 0.37$ \\
\hline 3 & S. nigra hydroalcoholic extract $(200 \mathrm{mg} / \mathrm{kg})$ & $28.32 \pm 0.67^{*}$ & $3 \pm 0.316$ & $69.8 \pm 1.6$ & $6.6 \pm 0.4$ \\
\hline 4 & S. nigra hydroalcoholic extract (400 mg/kg) & $27.54 \pm 0.98^{\star *}$ & $2.8 \pm 0.374$ & $70.6 \pm 1.6$ & $6.6 \pm 0.4$ \\
\hline 5 & Standard diazepam $(1 \mathrm{mg} / \mathrm{kg})$ & $26 \pm 2.07^{\star * *}$ & $2.6 \pm 0.2^{*}$ & $73 \pm 1.28^{*}$ & $6.2 \pm 0.37$ \\
\hline
\end{tabular}

Value are expressed as percentage way $(n=5)$, one way ANOVA followed by Dunnett's test; ${ }^{\text {a }} P<0.001$ when compared to normal control ${ }^{\mathrm{b}} P<0.5,0.1,0.05$, when compared with the stress group.

of SGPT, SGOT and ALP in comparison to the stress control group. Corticosterone mediated enhanced metabolism may be attributed to meet the increased demands of the body organs during stress. ${ }^{32-33}$

As above described of stress mechanism, lipids were mobilized from adipose tissues due to the liberation of corticosterone from the adrenal cortex. Lipid profiles levels (TG, TC, HDL, LDL, and VLDL) altered after exposure of rats to cold stress. The $400 \mathrm{mg} / \mathrm{kg}$ dose of $S$. nigra hydroalcoholic extract caused a significant restoration in the altered lipid profiles levels.

The method used in this study employs mild electroshock Stress, unpredictable in nature, administered over a period of two weeks. There is considerable experimental and clinical evidence to suggest that chronic induces endogenous depression. A number of animal models of depression are based on the use of uncontrollable stress and the biochemical correlates of such tests are consonant with those seen in chronic stress.

Both S. nigra hydroalcoholic extract and diazepam were able to reverse chronic stress-induced indices validated as animal models of depression.
Chronic stress is known to affect other endocrine responses as well, which can induce sexual debility in males. ${ }^{34}$

Foot shock characterizes the unpredictable and inescapable nature of stress. $^{35}$

Chronic exposure to foot shock disrupts body's own adaptation process and results stress mediated perturbations including cognitive dysfunction, and behavioural depression. ${ }^{36}$ Chronic Footshock stress induced depression in male sexual behaviour observed in control group. ${ }^{37}$

S. nigra hydroalcoholic extract and diazepam reversed chronic stressinduced inhibition of male sexual behaviour.

Stress is known to interfere with cognitive functions, tending to retard the memory engram rather than the acquisition of learning. The mechanisms involved in the memory-attenuating effect of stress remains conjectural but a similar neurochemical basis operating in the induction of stress-induced depression, may be responsible" ${ }^{38-39}$ S. nigra hydroalcoholic extract and diazepam attenuated the stressinduced deficit of retention of learned tasks. 
Kaempferol are widely distributed polyphenolic flavanoid compounds in nature. These flavanols possess antioxidant, anti-inflammatory, cytotoxic $^{40}$ analgesic ${ }^{41}$, and antimicrobial ${ }^{42}$ and many wide ranges of activities.

Several theories have been recommended to describe the effects of adaptogenic substances. One theory claims that adaptogens function mainly due to their antioxidant effect which is found to be partially accurate. ${ }^{43}$ S. nigra contain kaempferol confirmed by IR spectrum had potent antioxidant activity which was mainly contributed adaptogenic activity.

Thus, the dose $400 \mathrm{mg} / \mathrm{kg}$ of $S$. nigra hydroalcoholic extract has markedly affected on biochemical parameters (liver function test, and lipid profile) and immunological levels (differential leukocyte count) as well as behaviour perturbations in which exhibited nearly effect to that of standard diazepam drug.

The present investigation shows that the $S$. nigra hydroalcoholic extract has significant adaptogenic activity as shown by its alleviating effects on several chronic stress induced biochemical, physiological and behaviour perturbations, comparable to that induced by the wellestablished standard adaptogenic drug diazepam.

\section{REFERENCES}

1. Kopp MS, Rethelyi J. Where psychology meets physiology: chronic stress and premature mortality - the Central-Eastern European health paradox. Brain research bulletin. 2004;62(5):351-67.

2. Stults-Kolehmainen MA, Sinha R. The effects of stress on physical activity and exercise. Sports medicine. 2014;44(1):81-121.

3. Dickens MJ, Delehanty DJ, Romero LM. Stress: an inevitable component of animal translocation. Biological Conservation. 2010;143(6):1329-41.

4. Kumar B, Kuhad A, Chopra K. Neuropsychopharmacological effect of sesamol in unpredictable chronic mild stress model of depression: behavioral and biochemical evidences. Psychopharmacology. 2011;214(4):819-28.

5. Habbu PV, Mahadevan KM, Kulkarni PV, Daulatsingh C, Veerapur VP, Shastry RA Adaptogenic and in vitro antioxidant activity of flavanoids and other fractions of Argyreia speciosa (Burm. f) Boj. in acute and chronic stress paradigms in rodents. Indian Journal of Experimental Biology. 2010;48:53-60.

6. Habbu PV, Smita DM, Mahadevan KM, Shastry RA, Biradar SM. Protective effect of Habenaria intermedia tubers against acute and chronic physical and psychological stress paradigms in rats. Revista Brasileira de Farmacognosia. 2012;22(3):568-79

7. Nagasirisha M, Saleem TM. Effect of whole plant of Rostellularia diffusa Willd. on experimental stress in mice. Pharmacognosy Magazine. 2014;10(3):614

8. Habbu PV, Smita DM, Mahadevan KM, Shastry RA, Biradar SM. Protective effect of Habenaria intermedia tubers against acute and chronic physical and psychological stress paradigms in rats. Revista Brasileira de Farmacognosia. 2012 Jun;22(3):568-79

9. Zhang XL, Ren F, Huang W, Ding RT, Zhou OS, Liu XW. Anti-fatigue activity of extracts of stem bark from Acanthopanax senticosus. Molecules. 2011;16(1):2837.

10. Rai D, Bhatia G, Sen T, Palit G. Anti-stress effects of Ginkgo biloba and Panax ginseng: a comparative study. Journal of pharmacological sciences. 2003;93(4):458-64

11. Bharathi KN, Sivaramaiah N, Nagarjuna CG, Gupta AV. Evaluation of antistress, anxiolytic and hypnotic activity of vedic calm, a polyherbal formulation. Pharmacognosy Magazine. 2009; 5(19):124-130.

12. Sumnath M, Mustafa SS. Antistress, adaptogenic activity of sida cordifolia. Indian J Pharmacol Sci. 2009; 71(3):323-4

13. Gupta P, Yadav DK, Siripurapu KB, Palit G, Maurya R. Constituents of Ocimum sanctum with antistress activity. Journal of natural products. 2007;70(9):1410 6.

14. Soman I, Mengi SA, Kasture SB. Effect of leaves of Butea frondosa on stress, anxiety, and cognition in rats. Pharmacology biochemistry and behavior. 2004 ;79(1):11-6

15. Kumar V, Singh PN, Jaiswal AK, Bhattacharya SK. Antidepressant activity of Indian Hypericum perforatum Linn in rodents. Indian Journal of Experimental Biology 1999;37: 1171-1176.

16. Azari B, Siami A, Ebrahimzadeh MA, Khan BA. Antioxidants activity of extracts from Sambucus nigra, efficiency of different extraction methods. Lat Am Appl Res. 2015;45:139-44.
17. Panossian A, Wikman G. Evidence-based efficacy of adaptogens in fatigue and molecular mechanisms related to their stress-protective activity. Current clinical pharmacology. 2009 Sep 1;4(3):198-219.

18. Dawidowicz AL, Wianowska D, Baraniak B. The antioxidant properties of alcoholic extracts from Sambucus nigra L.(antioxidant properties of extracts). LWT-Food Science and Technology. 2006;39(3):308-15.

19. Ataee R, Falahati A, Ebrahimzadeh MA, Shokrzadeh M. Anticonvulsant activities of Sambucus nigra. Eur Rev Med Pharmacol Sci. 2016 Jul 1;20(14):3123-6.

20. Telange DR, Patil AT, Pethe AM, Tatode AA, Anand S, Dave VS. Kaempferolphospholipid complex: formulation, and evaluation of improved solubility, in vivo bioavailability, and antioxidant potential of kaempferol. Journal of excipients and food chemicals. 2016;7(4):1174.

21. Kannur D, Nandanwadkar S, Dhawane S, Phulambrikar S, Khandelwal K Experimental evaluation of Hygrophila Schulli seed extracts for antistress activity. Ancient Science of Life. 2017;37(1):31.

22. Armando I, Lemoine AP, Segura ET, Barontini MB. The stress-induced reduction in monoamine oxidase (MAO) A activity is reversed by benzodiazepines: role of peripheral benzodiazepine receptors. Cellular and molecular neurobiology. 1993;13(6):593-600

23. Nade VS, Kawale LA, Naik RA, Yadav AV. Adaptogenic effect of Morus alba on chronic footshock-induced stress in rats. Indian journal of pharmacology. 2009;41(6):246.

24. Hill MN, Gorzalka BB. Pharmacological enhancement of cannabinoid CB1 receptor activity elicits an antidepressant-like response in the rat forced swim test. European Neuropsychopharmacology. 2005;15(6):593-9.

25. Singh, G. K., Rai, G., Chatterjee, S. S., \& Kumar, V. (2012). Beneficial effects of Fumaria indica on chronic stress-induced neurobehavioral and biochemical perturbations in rats.

26. Bhattacharya, S. K., Bhattacharya, A., \& Chakrabarti, A. (2000). Adaptogenic activity of Siotone, a polyherbal formulation of Ayurvedic Rasayanas. Indian Journal of Experimental Biology, 38, 119-128.

27. Huther $\mathrm{G}$. The central adaptation syndrome: psychosocial stress as a trigger for adaptive modifications of brain structure and brain function. Progress in neurobiology. 1996 Apr 1;48(6):569-612

28. Bhatia N, Maiti PP, Choudhary A, Tuli A, Masih D, Khan MM, Ara T, Jaggi AS Animal models of stress. International Journal of Pharmaceutical Sciences and Research. 2011 May 1;2(5):1147.

29. Sutanto W, De Kloet ER. The use of various animal models in the study of stress and stress-related phenomena. Laboratory Animals. 1994;28(4):293-306.

30. Lailatussifa R, Husni A, Nugroho AE. Anti-stress activity of Sargassum polycystum extracts using a cold restraint stress model. Food science and biotechnology. 2016 Apr 1;25(2):589-94.

31. Barua, C.C., Patowary, P., Roy, J.D., Pathak, D.C., Bordoloi, M.J. and Barua, I.C., 2018. Ameliorating effect of Gnetumgnemon L. on hypothalamic pituitary adrenal axis during acute and chronic stress in rats. Indian Journal of Experimental Biology, 17:240-246.

32. Wu C, Chen R, Wang XS, Shen B, Yue W, Wu Q. Antioxidant and anti-fatigue activities of phenolic extract from the seed coat of Euryale ferox Salisb. and identification of three phenolic compounds by LC-ESI-MS/MS. Molecules. 2013;18(9):11003-21.

33. Ben Othman M, Han J, El Omri A, Ksouri R, Neffati M, Isoda H. Antistress effects of the ethanolic extract from Cymbopogon schoenanthus growing wild in Tunisia. Evidence-Based Complementary and Alternative Medicine. 2013;2013

34. Bouwknecht JA, Olivier B, Paylor RE. The stress-induced hyperthermia paradigm as a physiological animal model for anxiety: a review of pharmacological and genetic studies in the mouse. Neuroscience \& Biobehavioral Reviews. 2007 Jan 1;31(1):41-59

35. Bhattacharya A, Muruganandam AV, Kumar V, Bhattacharyya SK, Effect of polyherbal formulation Eumil on neurochemical perturbations induced by chronic stress, Ind J Exp Biol, 40 (2002) 1161-3.

36. Nade VS, Kawale LA, Naik RA, Yadav AV. Adaptogenic effect of Morus alba on chronic footshock-induced stress in rats. Indian journal of pharmacology. 2009;41(6):246.

37. Kannur D, Kulkarni A, Paranjpe M, Navangul M. Screening of antistress properties of herbal extracts and adaptogenic agents-A review. Pharmacognosy Reviews. 2008;2(3):95

38. Baran SE, Armstrong CE, Niren DC, Hanna JJ Conrad CD Chronic stress and sex differences on the recall of fear conditioning and extinction. Neurobiology of learning and memory. 2009;91(3):323-32.

39. Muruganandam AV, Kumar $\bigvee$, Bhattacharyya SK. Effect of polyherbal formulation, Eumil on chronic stress induced homeostasic perturbations in rats. Ind J Expt Biol, 40 (2002) 1151-1160.

40. Wang J, Fang X, Ge L, Cao F, Zhao L, Wang Z, Xiao W. Antitumor, antioxidant and anti-inflammatory activities of kaempferol and its corresponding glycosides and the enzymatic preparation of kaempferol. PLoS One. 2018;13(5):e0197563. 
41. Parveen Z, Deng Y, Saeed MK, Dai R, Ahamad W, Yu YH. Antiinflammatory and analgesic activities of Thesium chinense Turcz extracts and its major flavonoids, kaempferol and kaempferol-3-O-glucoside. Yakugaku Zasshi. 2007 Aug 1;127(8):1275-9

42. del Valle P, García-Armesto MR, de Arriaga D, González-Donquiles C, RodríguezFernández P, Rúa J. Antimicrobial activity of kaempferol and resveratrol in binary combinations with parabens or propyl gallate against Enterococcus faecalis. Food Control. 2016 Mar 1;61:213-20.

43. Popovic, Z., Smiljanic, M., Kostic, M., Nikic, P., \& Jankovic, S. (2014). Wild flora and its usage in traditional phytotherapy (Deliblato Sands, Serbia, South East Europe). Indian Journal of Traditional Knowledge, 13, 9-35.

\section{GRAPHICAL ABSTRACT}

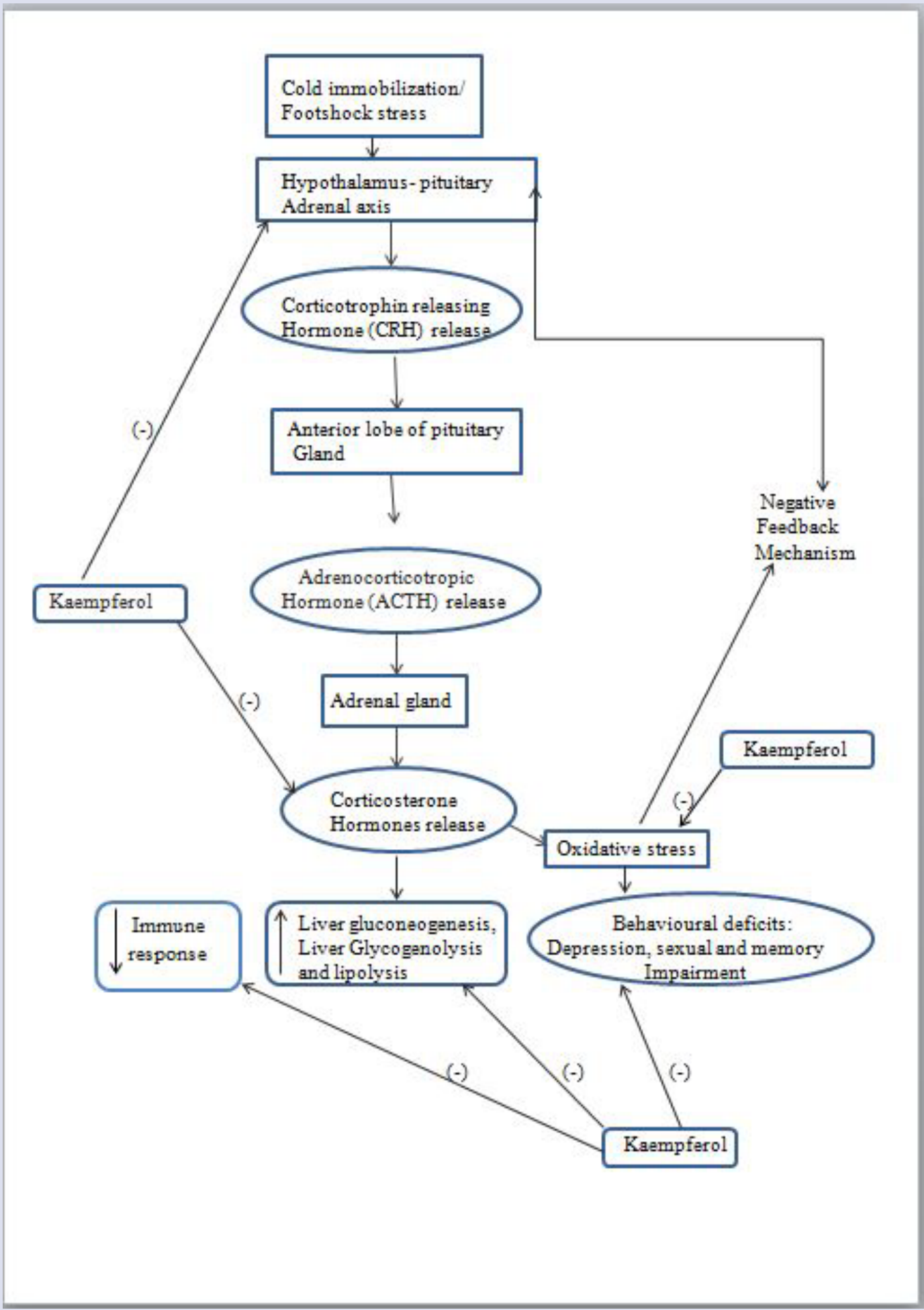




\section{ABOUT AUTHORS}

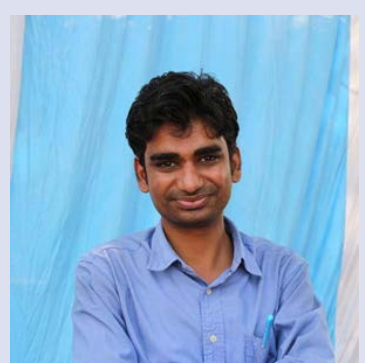

Sachin Neekhra is PhD student of the Pharmaceutical science in Amity Institute of Pharmacy, Amity University Uttar Pradesh, Lucknow. He is working on neuropharmacological and adaptogenic activities of different plant extracts on rodents. He has published many articles on adaptogenic activity.

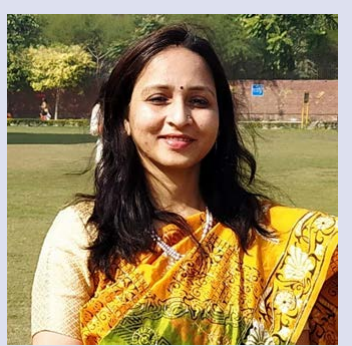

Himani Awasthi is an Associate Professor at the Amity Institute of Pharmacy, Amity University Uttar Pradesh, Lucknow. She has published various articles in neurodegenerative disorder management drug and adaptogenic activity. She has experience in the area of Pharmacology, neuropharmacology and ethnopharmacology areas.

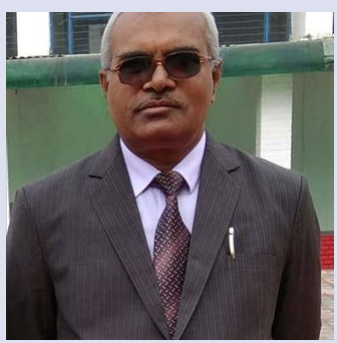

Dharmchand Prasad Singh is professor at College of Pharmacy, SR Group of Institutions, Jhansi. He has published many articles on medicinal Chemistry specially synthesis of drug, neuropharmacology and adaptogenic activity. He has 29-year experiences in teaching and research field in the area of Medicinal Chemistry.

Cite this article: Neekhra S, Awasthi H, Singh DCP. Beneficial Effects of Sambucus nigra in Chronic Stress-Induced Neurobehavioral and Biochemical Perturbation in Rodents. Pharmacog J. 2021;13(1): 155-61. 